\title{
A comparison of techniques for measuring hue appearance*
}

\author{
MICHAEL H. SIEGEL and ANNE B. SIEGEL \\ Albion College, Albion, Michigan 49224
}

Three different techniques for the direct measurement of color appearance were studied. Color estimation proved superior both to color naming and to color setting. The results have defined one technique in generating a color metric.

A successful and meaningful metric of color space is possible, we feel, only by combining results from color discrimination studies with those from the measurement of color appearance. The present report is concerned with establishing a technique to measure color appearance directly.

For some time the "direct" measurement of color appearance was conducted only rarely. More recently, however, this kind of study has become more popular (Yager \& Taylor, 1970). Certainly the most frequently used technique has been color naming (Boynton, Schafer, \& Neun, 1964). This method has proved reliable, requires a relatively simple judgment from the $O$, and is appropriate for studying a wide range of visual problems.

The color-naming technique is not completely free from problems. It has already been noted that the choice of naming categories available for the $\mathrm{O}$ is critical. It is not enough, then, to know that two different studies used a color-naming technique. In order to make comparisons meaningful, the available categories must be the same (Beare \& Siegel, 1967).

Another difficulty with the color-naming procedures is that no matter how many naming categories are made available for the $O$, his subjective impression is that he is not conveying all the information about the stimulus. Indeed, even if the choice of color name is left exclusively to the $O$, his color language is simply not sufficiently complete to describe anything like the myriad differences among color that he can detect.

The present report describes an attempt to evaluate the color-naming technique and to compare it to two alternative ways to specify color appearance.

\section{METHOD}

\section{Observers}

Seven different Os were used. Six had not formerly participated in color vision experiments and one, the senior author, had served in many similar studies. No differences were found among the Os; therefore, only the senior author's graphic data are presented. Tabular data are presented for all Os. In each case, the $O$ used his right eye to observe the stimuli; the left eye was occluded.

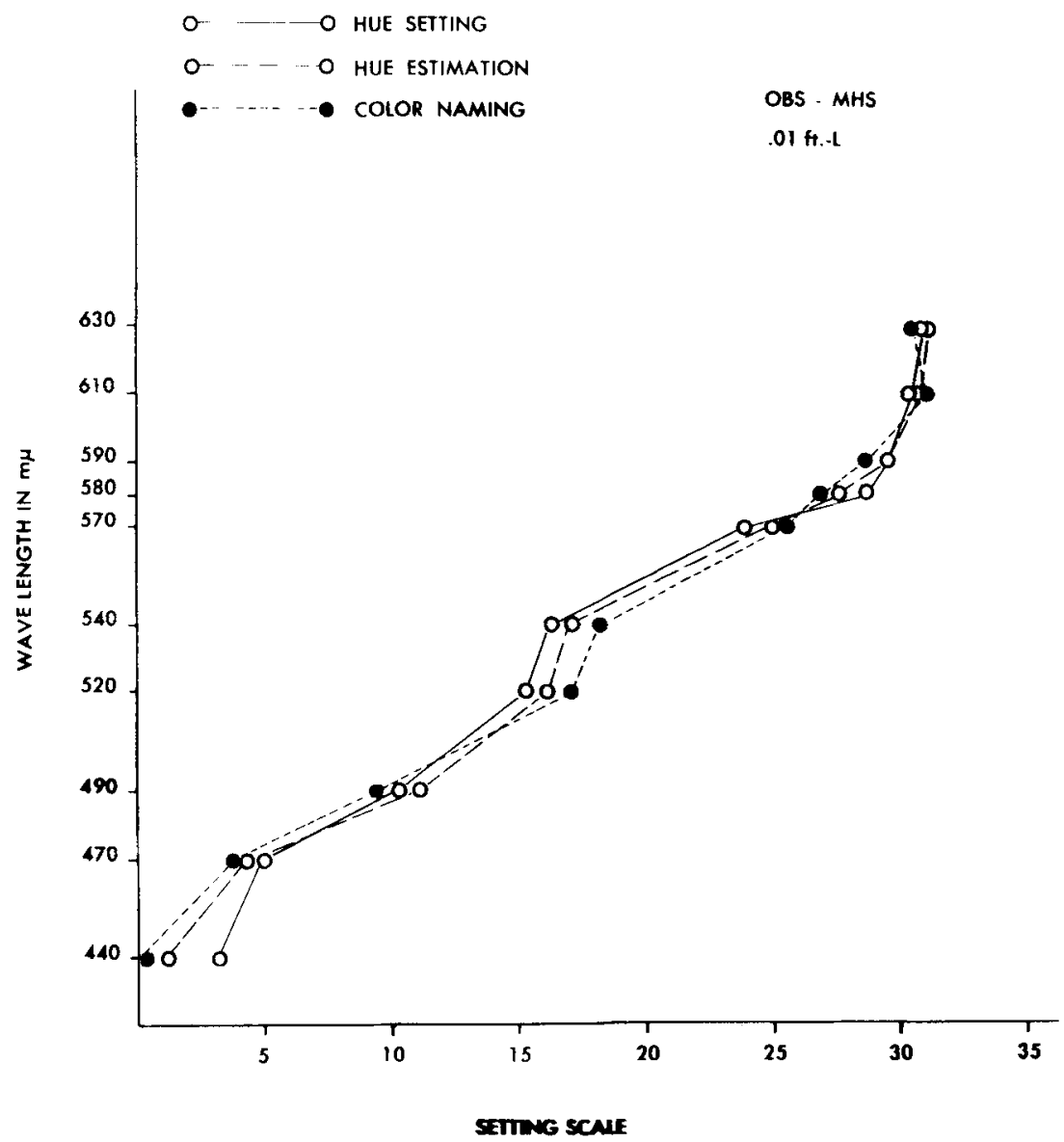

Fig. 1. Hue setting, hue estimation, and color naming as a function of wa velength. Data are for $.01 \mathrm{fL}$.
Apparatus

Colored stimuli were produced by a Bausch and Lomb 500-mm grating monochromator. The stimulus field was circular, subtended $3 \mathrm{deg}$ at the $O$ 's eye, and could be exposed for .2-sec flashes. Each stimulus could be set, by means of a filter system, to any of three different Juminance levels: $.01,1.0$, and $100 \mathrm{fL}$. The area surrounding the stimulus was white; the color temperature was approximately that of Illuminant $C$ and was maintained at a luminance of $1.0 \mathrm{fL}$ throughout the experiment. Stimulus luminance was defined by equating the brightness of the stimulus field to that of the white surround. The luminance of the surround was obtained with a Spectra-Brightness spot meter, UB $1 \frac{1}{2}$. Calibrations made
Portions of this paper appear in the Proceedings of Color 69 Meeting, Stockholm, Sweden, 1969. 
Table 1

Color-Naming Technique: Mean Hue Scores for All Os

\begin{tabular}{|c|c|c|c|c|c|c|c|c|c|c|c|}
\hline \multirow{2}{*}{$\begin{array}{l}\text { Luminance } \\
\text { (fL) }\end{array}$} & \multirow[b]{2}{*}{ Observer } & \multicolumn{10}{|c|}{ Wavelength in $\mathrm{nm}$} \\
\hline & & 440 & 470 & 490 & 520 & 540 & 570 & 580 & 590 & 610 & 630 \\
\hline \multirow{7}{*}{100} & 1 & 3.45 & 5.00 & 8.11 & 17.45 & 18.11 & 21.89 & 28.11 & 28.56 & 31.67 & 32.11 \\
\hline & 2 & 5.00 & 5.00 & 15.00 & 17.23 & 19.23 & 25.00 & 25.89 & 27.67 & 34.78 & 35.00 \\
\hline & 3 & 5.00 & 5.00 & 8.34 & 19.23 & 19.45 & 25.00 & 25.56 & 28.34 & 34.56 & 35.00 \\
\hline & 4 & 5.00 & 5.00 & 9.23 & 18.11 & 18.78 & 24.56 & 25.00 & 28.34 & 33.45 & 35.00 \\
\hline & 5 & 5.00 & 5.00 & 7.00 & 16.78 & 18.56 & 23.00 & 27.00 & 31.22 & 35.00 & 35.00 \\
\hline & 6 & 4.78 & 5.00 & 11.67 & 17.23 & 20.11 & 24.78 & 25.23 & 29.00 & $\mathbf{3 4 . 5 6}$ & 35.00 \\
\hline & 7 & 5.00 & 5.00 & 8.78 & 17.89 & 20.11 & 25.00 & 25.67 & 28.34 & 31.89 & 34.34 \\
\hline \multirow{7}{*}{1.0} & 1 & $\mathbf{0}$ & 4.56 & 9.45 & 16.33 & 16.78 & 23.89 & 27.89 & 29.00 & 33.00 & 34.78 \\
\hline & 2 & 5.00 & 6.34 & 12.56 & 15.89 & 18.11 & 24.56 & 26.11 & 30.11 & 33.67 & 35.00 \\
\hline & 3 & 39.45 & 5.00 & 10.56 & 15.89 & 18.56 & 25.00 & 27.00 & 30.56 & 35.00 & 35.00 \\
\hline & 4 & 3.45 & 5.00 & 10.56 & 15.23 & 15.67 & 22.56 & 24.78 & 29.00 & 34.78 & 35.00 \\
\hline & 5 & 3.45 & 5.00 & 10.56 & 15.00 & 15.23 & 17.89 & 27.23 & 34.11 & 35.00 & 35.00 \\
\hline & 6 & 0 & 5.34 & 14.56 & 15.23 & 16.34 & 23.45 & 25.45 & 29.45 & 34.34 & 34.34 \\
\hline & 7 & 1.89 & 5.00 & 9.45 & 12.56 & 15.89 & 21.45 & 28.56 & 30.34 & 34.11 & 35.00 \\
\hline \multirow{7}{*}{.01} & 1 & 0 & 3.89 & 9.45 & 17.22 & 18.11 & 25.45 & 27.23 & 29.00 & 31.23 & 31.00 \\
\hline & 2 & 5.00 & 5.45 & 12.34 & 16.34 & 18.56 & 25.45 & 27.00 & 28.56 & 31.67 & 31.89 \\
\hline & 3 & 38.34 & 0 & 10.34 & 15.23 & 19.00 & 25.00 & 25.11 & 29.23 & 30.78 & 32.34 \\
\hline & 4 & 39.45 & 5.00 & 13.00 & 15.00 & 15.23 & 22.34 & 25.67 & 26.78 & 31.50 & 32.11 \\
\hline & 5 & 2.78 & 5.00 & 9.23 & 15.00 & 17.00 & 25.22 & 27.44 & 34.33 & 34.78 & 34.11 \\
\hline & 6 & .56 & 4.34 & 15.67 & 18.34 & 18.56 & 25.00 & 25.45 & 27.45 & 30.34 & 30.34 \\
\hline & 7 & 0 & 6.11 & 9.67 & 11.89 & 11.89 & 21.23 & 27.67 & 30.56 & 34.34 & 35.00 \\
\hline
\end{tabular}

Table 2

Hue Setting Technique: Mean Hue Score for All Os

\begin{tabular}{|c|c|c|c|c|c|c|c|c|c|c|c|}
\hline \multirow{2}{*}{$\begin{array}{c}\text { Luminance } \\
\text { (fL) }\end{array}$} & \multirow[b]{2}{*}{ Observer } & \multicolumn{10}{|c|}{ Wavelength in $\mathrm{nm}$} \\
\hline & & 440 & 470 & 490 & 520 & 540 & 570 & 580 & 590 & 610 & 630 \\
\hline \multirow{7}{*}{100} & 1 & 4.80 & 5.07 & 9.33 & 16.13 & 16.60 & 23.47 & 26.07 & 30.07 & 34.00 & 34.27 \\
\hline & 2 & 5.20 & 5.93 & 14.73 & 15.33 & 16.60 & 24.67 & 26.27 & 28.07 & 34.27 & 35.47 \\
\hline & 3 & 4.93 & 5.00 & 6.87 & 16.87 & 19.33 & 24.73 & 25.60 & 30.13 & 35.73 & 35.67 \\
\hline & 4 & 5.00 & 5.00 & 10.53 & 17.47 & 19.53 & 24.67 & 25.87 & 27.73 & 34.73 & 35.20 \\
\hline & 5 & 4.80 & 5.00 & 7.33 & 18.20 & 18.93 & 21.73 & 26.20 & 30.80 & 35.13 & 35.33 \\
\hline & 6 & 4.87 & 5.00 & 13.87 & 16.27 & 18.80 & 24.93 & 25.67 & 29.67 & 34.87 & 35.80 \\
\hline & 7 & 5.00 & 5.47 & 9.93 & 17.60 & 19.20 & 24.40 & 25.00 & 29.73 & 32.20 & 34.27 \\
\hline \multirow{7}{*}{1.0} & 1 & 3.60 & 5.00 & 11.13 & 15.20 & 16.27 & 24.00 & 26.60 & 29.80 & 33.93 & 34.47 \\
\hline & 2 & 4.93 & 7.87 & 13.27 & 14.80 & 15.60 & 22.73 & 25.67 & 27.73 & 32.53 & 33.40 \\
\hline & 3 & 0.13 & 5.00 & 13.07 & 15.40 & 16.53 & 24.73 & 25.53 & 30.20 & 35.47 & 36.00 \\
\hline & 4 & 2.53 & 4.93 & 13.13 & 15.80 & 16.13 & 22.53 & 25.20 & 28.93 & 34.80 & 35.53 \\
\hline & 5 & 3.33 & 4.93 & 10.60 & 14.93 & 15.00 & 18.20 & 28.93 & 34.93 & 35.40 & 35.40 \\
\hline & 6 & 2.00 & 5.00 & 13.87 & 15.00 & 15.40 & 24.93 & 25.80 & 29.27 & 34.53 & 35.87 \\
\hline & 7 & 1.13 & 5.20 & 10.60 & 13.73 & 12.40 & 20.27 & 24.27 & 32.27 & & 34.47 \\
\hline \multirow{7}{*}{.01} & 1 & 2.93 & 5.00 & 10.27 & 15.47 & 16.27 & 24.27 & 27.93 & 29.73 & 30.60 & 31.07 \\
\hline & 2 & 3.47 & 7.53 & 13.07 & 16.27 & 18.26 & 24.13 & 26.07 & 26.80 & 30.93 & 31.27 \\
\hline & 3 & 39.33 & 4.73 & 14.40 & 16.13 & 21.00 & 24.87 & 25.13 & 26.27 & 31.13 & 30.60 \\
\hline & 4 & 0.27 & 4.73 & 13.93 & 16.00 & 15.47 & 23.80 & 24.87 & 26.67 & 30.27 & 31.60 \\
\hline & 5 & 2.00 & 5.00 & 10.80 & 15.00 & 14.93 & 21.20 & 33.33 & 35.07 & 35.27 & 35.13 \\
\hline & 6 & 1.60 & 4.93 & 14.27 & 15.27 & 15.80 & 24.93 & 25.33 & 27.87 & 30.93 & 31.93 \\
\hline & 7 & 0.47 & 5.33 & 12.07 & 13.87 & 13.80 & 20.00 & 25.53 & 32.13 & 34.00 & 34.33 \\
\hline
\end{tabular}

before and after experimentation response from the $O$. In color naming, revealed no differences in the the $O$ chose one of four color names, luminance levels of the stimulus, the or their appropriate compounds, to surround, or the duration of the the stimulus. The response categories exposure.

\section{Procedure}

Ten wavelength settings, from 440 through $630 \mathrm{~nm}$ in intervals of 10 to $30 \mathrm{~nm}$, were selected. An effort was made to sample the spectrum in such a way that the unique colors as well as some intermediate colors were included. Each wavelength was presented at each of the three luminance levels so that 30 stimuli were presented in a mixed order.

Three experimental techniques were used, each requiring a different the stimulus. The response categories
available were: red, red-yellow, yellow-red, yellow, yellow-green, green-yellow, green, green-blue, blue-green, blue, blue-red, and red-blue. An experimental session, usually lasting about $1 \mathrm{~h}$, consisted of three separate presentations of the 30 stimuli. The $\mathrm{O}$ was instructed to respond as quickly as possible without "thinking about" the color and to name the dominant color first.

In the color-setting technique, the $O$ was supplied with a pointer free to rotate $360 \mathrm{deg}$, mounted in a box, the corners of which were labeled red, yellow, green, and blue. The pointer was connected to a potentiometer, which in turn was connected to a microammeter, so that the $\mathrm{E}$ could read the setting whole numbers from 0 to 40 . Both 0 and 40 represented the same color, a point midway between red and blue. The unique colors, at the corner positions, had the following settings: blue -5 , green-15, yellow-25, and red-35. The range of blues, for example, extended from 0 to 10 on the E's scale and from a point midway along one side of the square box to a point midway along the adjacent side for the $O$, with the corner position (5) reserved for unique ("pure") blue. The setting of the microammeter was checked before 
Table 3

Hue Estimation Technique: Mean Hue Score for All Os

\begin{tabular}{|c|c|c|c|c|c|c|c|c|c|c|c|}
\hline \multirow{2}{*}{$\begin{array}{l}\text { Luminance } \\
\text { (fL) }\end{array}$} & \multirow[b]{2}{*}{ Observer } & \multicolumn{10}{|c|}{ Wavelength in $\mathrm{nm}$} \\
\hline & & 440 & 470 & 490 & 520 & 540 & 570 & 580 & 590 & 610 & 630 \\
\hline \multirow{7}{*}{100} & 1 & 4.33 & 5.00 & 10.13 & 17.00 & 17.73 & 24.13 & 26.67 & 29.87 & 33.47 & 34.40 \\
\hline & 2 & 6.07 & 7.67 & 14.53 & 15.27 & 20.13 & 25.53 & 27.80 & 29.80 & 34.53 & 34.93 \\
\hline & 3 & 5.00 & 5.00 & 6.87 & 17.27 & 18.27 & 25.87 & 27.73 & 29.53 & 33.20 & 34.67 \\
\hline & 4 & 5.00 & 5.00 & 9.67 & 18.60 & 19.33 & 24.73 & 25.47 & 26.73 & 33.20 & 34.40 \\
\hline & 5 & 5.00 & 5.13 & 6.80 & 20.07 & 19.80 & 24.40 & 27.87 & 29.53 & 35.00 & 35.00 \\
\hline & 6 & 5.00 & 5.00 & 13.13 & 15.87 & 19.13 & 25.00 & 26.13 & 28.40 & 34.20 & 35.00 \\
\hline & 7 & 5.00 & 5.00 & 10.00 & 16.53 & 20.20 & 25.07 & 26.40 & 29.87 & 32.00 & 34.53 \\
\hline \multirow{7}{*}{1.0} & 1 & 3.27 & 4.67 & 12.07 & 15.67 & 17.27 & 23.60 & 27.93 & 30.13 & 32.60 & 34.13 \\
\hline & 2 & 5.00 & 7.87 & 12.67 & 16.13 & 17.07 & 24.53 & 26.47 & 29.47 & 32.33 & 34.00 \\
\hline & 3 & 0.00 & 5.00 & 12.07 & 15.27 & 16.80 & 25.00 & 27.13 & 29.33 & 32.87 & 35.00 \\
\hline & 4 & 3.33 & 5.00 & 12.07 & 14.93 & 16.07 & 20.67 & 25.33 & 27.80 & 32.60 & 34.80 \\
\hline & 5 & 4.00 & 5.80 & 11.93 & 15.07 & 15.67 & 24.47 & 35.00 & 34.87 & 35.00 & 35.00 \\
\hline & 6 & 1.60 & 4.93 & 13.60 & 14.53 & 16.00 & 25.00 & 26.20 & 29.67 & 33.60 & 35.00 \\
\hline & 7 & 3.40 & 5.00 & 9.80 & 12.80 & 13.60 & 21.93 & 27.27 & 31.20 & 34.33 & 34.93 \\
\hline \multirow{7}{*}{.01} & 1 & 2.20 & 4.53 & 11.20 & 16.40 & 17.10 & 25.13 & 27.53 & 29.60 & 31.00 & 31.53 \\
\hline & 2 & 3.00 & 8.60 & 12.87 & 16.08 & 18.13 & 24.07 & 27.67 & 29.93 & 32.20 & 32.33 \\
\hline & 3 & 0.00 & 5.00 & 13.60 & 16.93 & 17.33 & 25.00 & 26.60 & 27.87 & 30.07 & 30.27 \\
\hline & 4 & 1.73 & 5.00 & 11.87 & 15.00 & 17.00 & 22.47 & 24.53 & 27.27 & 30.53 & 30.07 \\
\hline & 5 & 1.93 & 5.80 & 10.27 & 15.13 & 15.13 & 25.67 & 32.13 & 34.53 & 35.00 & 35.00 \\
\hline & 6 & 1.33 & 4.87 & 13.93 & 14.60 & 14.53 & 25.00 & 26.40 & 27.87 & 30.73 & 31.60 \\
\hline & 7 & 2.60 & 5.00 & 9.07 & 10.47 & 11.80 & 19.13 & 28.13 & 31.27 & 32.93 & 33.73 \\
\hline
\end{tabular}

each experimental session and adjusted to true 0 . The pointer and the edges of the square box were coated with luminous tape so that the $O$ could see them in the semidarkened room. The $O$ 's task was to set the pointer to any

position he judged to represent the color of the stimulus. An experimental session, lasting about $1 \mathrm{~h}$, consisted of three separate presentations of the 30 stimuli.

In the color-estimation technique,

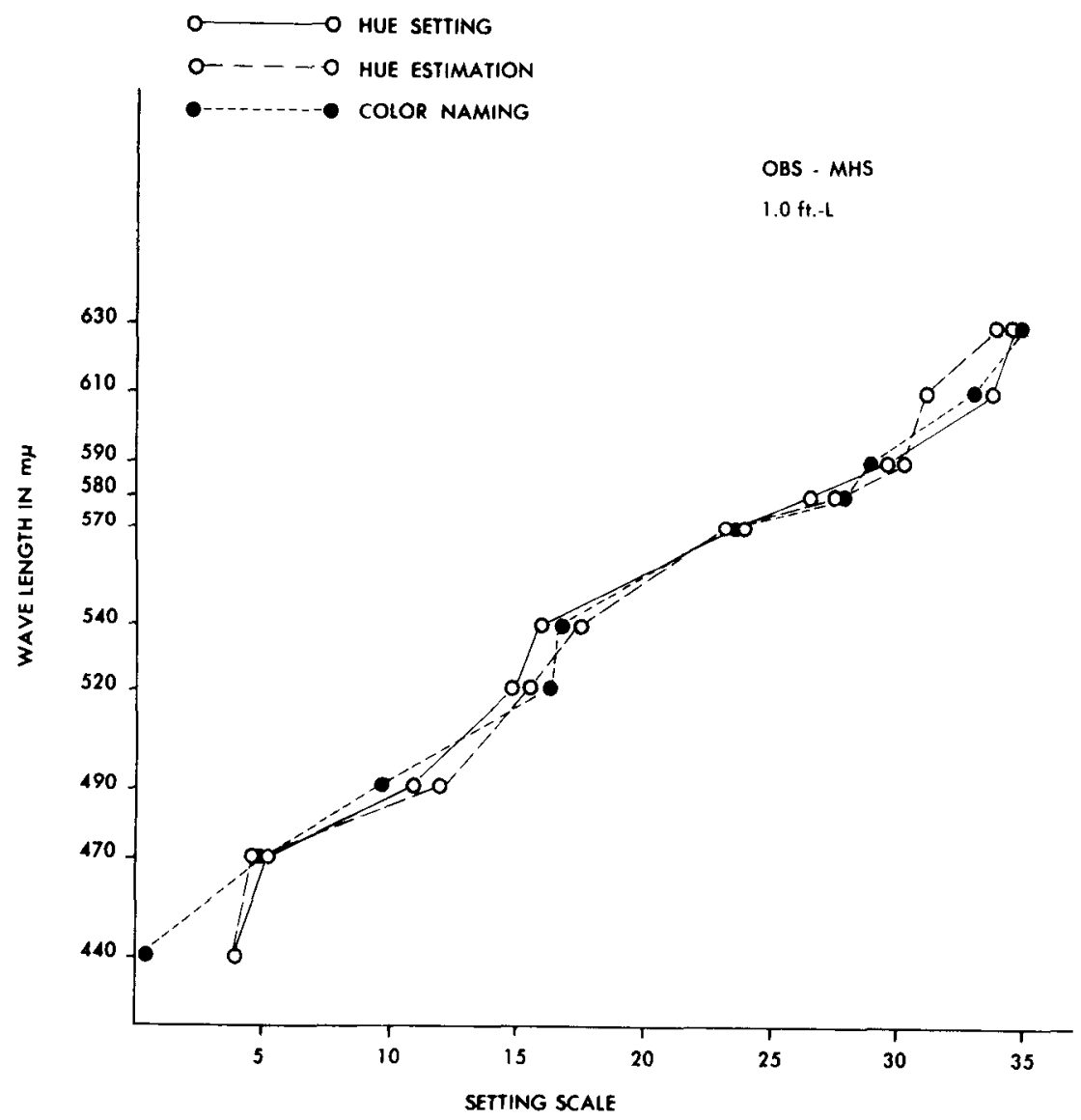

Fig. 2. Hue setting, hue estimation, and color naming as a function of wavelength. Data are for $1.0 \mathrm{fL}$. the $\mathrm{O}$ responded directly to the stimulus with a number from 0 through 40 , such that 5 represented unique blue, 15 unique green, 25 unique yellow, and 35 unique red. Other numbers represented intermediate colors, with both 0 and 40 indicating the point midway between red and blue. Here again an experimental session usually lasted about $1 \mathrm{~h}$ and consisted of three presentations of the stimuli.

In summary, the three techniques required a similar, though not identical, task from the Os. In color naming Os had only eight available response categories. In color setting the $O$ had the four corners of the response box to use as anchors and a continuous scale of intermediate responses. Of course, this was translated into a discrete number when the potentiometer was read. In color estimation, again the $O$ used four values as anchor points. Each of the four continua between any two adjacent unique colors provided a 10-point scale for the $O$.

\section{RESULTS}

Color names were converted into numbers from 0 through 40 so that the data from all three techniques could be compared. This was done by assigning the number 5 , for example, to blue and 15 to green and by assuming a linear spacing between 5 and 15. Therefore, blue-green was assigned the number 8.33 and green-blue the number 11.6. For all techniques a mean setting was calculated for each wavelength at each luminance level. Data for all techniques are presented in Tables 1-3. Although minor discrepancies may be seen in Fig. 1, among the curves at 


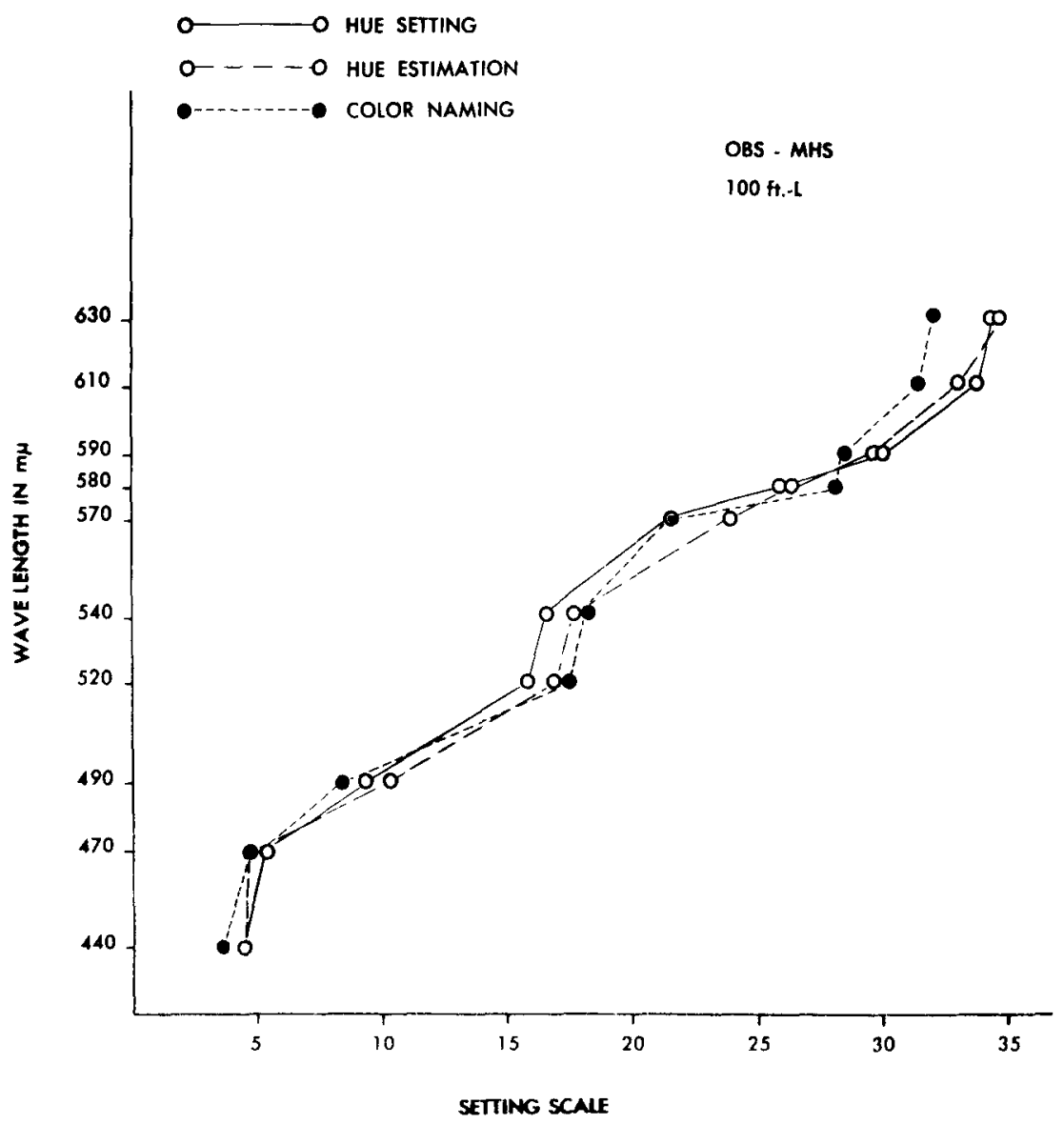

Fig. 3. Hue setting, hue estimation, and color naming as a function of wavelength. Data are for $100 \mathrm{fL}$.

$.01 \mathrm{fL}$, especially at the extremely short wavelengths, all three techniques yielded nearly identical curves. The color-naming technique tended to produce slightly lower setting values at the shortest wavelengths than did the other two techniques. This may have been due to the availability of only 12 color-name categories, whereas both other techniques had 40-point scales. At $1.0 \mathrm{fL}$ all three techniques again show virtual identity through most of the spectrum, as indicated in Fig. 2. At the shortest wavelength, color naming yields a " 0 " value (blue-red), while the other techniques only approach 0 . This might be accounted for by the absence of any other available category between it and blue. Other discrepancies are minor and not systematic.

At $100 \mathrm{fL}$, Fig. 3 shows that all three techniques once again produced

The major limitation of the present study came from the number of different stimuli employed. There were a total of 30 wavelength luminance combinations, which might seem to be enough; however, Os reported that the stimuli became familiar and were easily distinguished from one another. Once having made a response, there was a compelling tendency for $\mathrm{Os}$ to perseverate despite all attempts at objectivity. The information-processing capacity of the $O$ should be challenged by greatly increasing the number of different stimuli employed.

Since the three techniques produced virtually identical results, the question of which to select as most appropriate remains. Comments of the Os are of some value. From the Os' standpoint, the color-naming technique was least satisfying. Os frequently believed that they could make a greater number of color identifications than the color names provided could handle. As a result, some Os reported that they consistently called two different stimuli blue-green, although one was clearly bluer than the other. The fact that the final results for color naming were similar to those for the other two techniques is simply an indication that there was response variability and that averages were used.

Although the technical problems inherent in color setting were apparently solved by the Os, they had less confidence in this technique than they had in color estimation. Successful manipulation of the response indicator required the $\mathrm{O}$ to divert his fixation from the stimulus field to the pointer. With a dark surround, the luminous tape on the pointer and on the perimeter of the response box was not clearly visible, and $O$ s were at least partially dependent upon tactual and kinesthetic cues to locate the relative position of the pointer. In addition, the microammeter scale had to be recalibrated before each session and checked in midsession.

None of the Os had any difficulty in learning to associate a number with a color in the color-estimation technique. As the experiment progressed, it was clear that response latency decreased as Os gained more confidence with the technique. The color-estimation technique, then, was most appropriate for measuring color appearance.

\section{REFERENCES}

BEARE, A. C \& SIEGEL, M. H. Color name as a function of wavelength and instruction. Perception \& Psychophysics, 1967, 2, 521-527.

BOYNTON, R. M., SCHAFER, W., \& NEUN, M. E. Hue wavelength relation measure by color-naming method for three retinal locations. Science, 1964,

YAGER, E, \& TAYLOR, E. Experimental measures and theoretical account of hue scaling as a function of luminance. Perception \& Psychophysics, 1970, 7 , 360-364. $145,666-668$. 